LITERATURA 



\title{
EL MOTIVO DE LA CUNA VACÍA EN LA POESÍA LÍRICA POSROMÁNTICA ESPAÑOLA
}

\author{
Dorde Cuvardic García
}

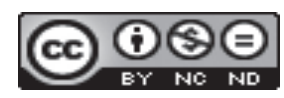

Esta obra está bajo una licencia Creative Commons

Reconocimiento-No Comercial-Sin Obra Derivada 



\title{
EL MOTIVO DE LA CUNA VACÍA EN LA POESÍA LÍRICA POSROMÁNTICA ESPAÑOLA
THE “EMPTY CRADLE” MOTIF IN SPANISH POST-ROMANTIC LYRICAL POETRY

\section{Dorde Cuvardic García}

\begin{abstract}
RESUMEN
La muerte infantil ha sido, en Occidente, uno de los principales temas de la poesía lírica. Y uno de los motivos de este tema es el de la cuna vacía, cuyo principal recurso discursivo es la perífrasis eufemística. En el presente artículo, realizaremos en primer lugar un recorrido por la poesía de la muerte infantil desde el Siglo de Oro hasta el siglo XX. En segundo lugar, situaremos el motivo de cuna vacía en el marco de la atenuación del dolor producido por la muerte de un hijo. Este objetivo es perseguido por la cultura de la cursilería, propugnada por la burguesía de la segunda mitad del siglo XIX. También se identifican en el presente artículo las más importantes manifestaciones poéticas del motivo de la cuna vacía, que estuvo en auge en el posromanticismo. Finalizaremos con un análisis de dos conocidas poesías que expresan este motivo, "La cuna vacía", de José Selgas, y "Dulce sueño", de Rosalía de Castro.

Palabras clave: cuna vacía, literatura española, niño muerto en la literatura, perífrasis eufemística, lírica siglo XIX.
\end{abstract}

\begin{abstract}
The infant death has been, in the West, one of the main themes of lyrical poetry. And one of the motifs of this theme is the empty cradle, whose main discursive resource is the euphemistic circumlocution. In this article, we will first tour the poetry of infant death from the Golden Age to the twentieth century. Secondly, we will place the empty crib motif within the attenuation of pain caused by the death of a child. This goal is pursued by the culture of kitsch advocated by the bourgeoisie of the second half of the nineteenth century. The most important poetic expressions of the empty cradle motif, which boomed in the post-Romanticism, are also identified in this article. We end with a discussion of two known poems that express this motif, "The Empty Cradle" by Jose Selgas, and "Sweet Dream" by Rosalia de Castro.

Key words: empty cradle, Spanish literature, dead child in literature, euphemistic circumlocution, nineteenth century poetry.
\end{abstract}

Dr. Dorde Cuvardic García. Universidad de Costa Rica. Escuela de Filología y Lingüística. Costa Rica. Correo electrónico: dcuvardic@yahoo.es

Recepción: 16- 01- 2014

Aceptación: 06- 02- 2014 


\section{Introducción}

Desde finales del siglo XVIII, la infancia se convierte en objeto de cuido y protección del proyecto ideológico burgués. Al mismo tiempo, los niños comienzan a ser centro de atención de la práctica literaria. En particular, un tema que obtiene representación en esta época es la muerte infantil (Ferrucci, 1989, pp. 117-118). Sobre un motivo específico de este acontecimiento luctuoso, el de la cuna vacía, centraremos las reflexiones del presente artículo.

Previamente, en todo caso, ya desde el Renacimiento y el Barroco encontramos numerosos casos de poesía lírica que tienen por tema la muerte de un niño. ${ }^{1}$ En ocasiones, se trata del hijo del propio poeta; en otras oportunidades, de un familiar o amistad. Dos ejemplos están representados por "Epitafio al túmulo del príncipe don Carlos", y "Canción a la muerte del mismo", de Fray Luis de León, preparados con motivo de la muerte de Carlos de Habsburgo (1545-1568). El más conocido de estos poemas del Siglo de Oro es "A la muerte de Carlos Félix”, integrado en las Rimas Sacras, de Lope de Vega, escrito a raíz del deceso de su propio hijo.

Ya en el Romanticismo, Ferrucci (1989, pp. 117-134) interpreta el motivo de la muerte de un niño como mito básico de este movimiento cultural. Analiza su eclosión en diversos autores (Goethe, William Wordsword, Rilke) desde una interpretación en clave metapoética: representar la mortalidad de un niño por medio de la poesía supone para el poeta -que asimismo ha sido caracterizado muchas veces como un 'alma infantil'-; alcanzar la inmortalidad como escritor.

También en el Romanticismo español se pueden distinguir diferentes poemas que siguen este tema. Sin que ofrezcamos un listado exhaustivo, es el caso de "La opinión. A mi querida prima Jacinta White de Llano, en la muerte de su hija", del poemario Doloras (1846), de Ramón de Campoamor. ${ }^{2}$ A su vez, Carolina Coronado lo representa en "Epitafio a un niño" (1844) y "En un álbum poético para una niña que se ahogó en el mar" (1850). Por su parte, José Zorrilla cuenta con "A la memoria del niño Ignacio Nestare y Bueno", y "Epitafio. En el sepulcro de un niño". ${ }^{3}$ También recrea este tema el Duque de Rivas en el poema "Elvira", que lleva la dedicatoria "A los señores duques de Rivona, en la muerte de su hija de este nombre, a los siete meses de edad", fechado en Nápoles el 17 de junio de 1845.

El venezolano Heriberto García de Quevedo cuenta con tres poemas sobre el tema de la muerte en la niñez: "En la muerte de un adolescente" (1857), "A mi sobrino Heriberto. El día que recibí la noticia de su fallecimiento" (1857) y "A la muerte de una niña" (1857). En la Cuba colonial, por su parte, se publicó el poema "En la muerte de un niño" (1851), de la colección Cantos de la tarde (1860), de Juan Clemente Zenea. Estos dos últimos poetas, García de Quevedo y Zenea, venezolano el primero y cubano el segundo, nos permiten demostrar que este tema también se practicó en el Romanticismo latinoamericano. ${ }^{5}$

Desde una actitud próxima a la del Posmodernismo latinoamericano, en la poesía de Unamuno, caracterizada en general por su contención emotiva, también se aprecia la representación del tema de la muerte infantil. En "Al niño enfermo", de Poesías (1907), el yo lírico se dirige al propio hijo, que expirará en breves momentos, mientras que en "A un hijo de españoles arropamos", de De Fuerteventura a París (1925), se refiere a una familia de emigrantes españoles en Francia que acaba de enterrar a su vástago. ${ }^{6}$

Desde la Generación del 27, Federico García Lorca representa el tema de la muerte del niño en "Romance de la luna, luna", del Romancero gitano (1927), donde el astro dialoga con el 
niño, que los gitanos encontrarán muerto a su llegada. En este caso, el papel positivo ocupado por el ángel en la representación del deceso del niño en la poesía romántica, mediador entre una vida corta dolorosa y una muerte llena de la esperanza del amor de Dios, queda sustituido por el símbolo trágico de la luna. La muerte de un niño también se tematiza en el escritor granadino en diversos poemas de Poeta en Nueva York. $^{7}$

Después de este recorrido histórico, el presente artículo se acercará a una modalidad lírica más específica de la muerte infantil. El objetivo es analizar el motivo Romántico y Posromántico de la cuna vacía. Cuando trabajamos con poemas que expresan este motivo, es una distinción irrelevante tratar de discernir en qué poemas se menciona o alude literalmente la muerte de un bebé 'en' la cuna, su lugar prototípico de descanso, y en qué casos no ocurre en este lugar, ya que con el nombre de este motivo, los poetas quieren designar, ante todo, la espiritualización de la muerte de un niño inocente de corta edad (antes de comenzar a articular sus primeras palabras) después de una dolorosa enfermedad, más allá de que el deceso haya ocurrido o no literalmente en una cuna. ${ }^{8}$ Se trata de un motivo elegíaco que se encuentra presente, sobre todo, en el Romanticismo y el Posromanticismo. Con este punto de partida, los objetivos del presente artículo consisten en explicar el porqué del favor que obtuvo en el siglo XIX, en identificar sus manifestaciones poéticas y pictóricas más conocidas y, por último, en analizar los procedimientos expresivos empleados en dos de sus más representativas muestras, "La cuna vacía", de Flores y espinas (1879), de José Selgas (1824-1882), y "Dulce sueño", de Hojas nuevas (1880), de Rosalía de Castro (1837-1885).

Hasta el momento no existe ningún estudio que permita comprobar, mediante la reunión de numerosas muestras, la amplia difusión del motivo de la cuna vacía en el Posromanticismo español, así como tampoco se ha publicado ningún estudio comparativo que analice los principales recursos retóricos, enunciativos y narrativos que ofrecen sus poemas más relevantes. El presente artículo pretende salvar estas carencias, presentes en el campo de estudios del Posromanticismo. A partir de estos objetivos, formulamos las siguientes preguntas de investigación: ¿Qué ejemplos del motivo de la cuna vacía se publicaron en el Posromanticismo? ¿Qué recursos retóricos, enunciativos y descriptivo-narrativos muestran los poemas más relevantes de este motivo literario? En este último rubro, analizaremos dos de los más conocidos poemas que ofrecen el motivo de la cuna vacía, procedentes de José Selgas y de Rosalía de Castro.

\section{El sentimentalismo posromántico burgués y la atenuación de la muerte infantil: la cuna vacía y la perífrasis eufemística}

La sociedad del siglo XIX es ambivalente cuando actúa sobre la niñez: mientras el burgués sobreprotege a su hijo y entona elegías ante su muerte prematura, en las fábricas de su propiedad mantiene en condiciones de explotación a niños obreros que trabajan doce horas diarias y que mueren, en muchos casos, por causas laborales. En estas coordenadas culturales, la vigencia del motivo de la cuna vacía se sitúa en una época, el siglo XIX, caracterizada por una gran preocupación por la mortalidad infantil.

El auge de este motivo ha de situarse en la necesidad que tiene la cultura burguesa de protegerse de lo que considera como amenazas a su afán de pervivencia, de eternidad. Una de ellas es la muerte del hijo, que supone la potencial desaparición del 'linaje' familiar. Como reacción, el hogar se convierte en un bastión que debe protegerse a toda costa. En el siglo XIX 
europeo -así como en la época isabelina y en el periodo de la Restauración borbónica, en el caso español-, la burguesía en ascenso buscaba convertir su casa en un universo independiente, seguro y protegido. ${ }^{9}$ Gómez de la Serna (1943, p. 35) no olvida este vínculo entre el repliegue hacia el interior de la burguesía decimonónica y lo cursi cuando declara que esta última categoría surge de "esa reacción a favor de la vida privada, viviéndose sin pensar en las tormentas que haya fuera” (Gómez de la Serna, 1943, p. 24). Es, finalmente, la estética más representativa de la doble moral burguesa:

Viene lo cursi del momento en que el hombre civil y aposentado se encuentra más consigo mismo y con sus seres amados y quiere hacer un microcosmos de su casa para cobijar en ella la paz, los tormentos íntimos y la felicidad. [...] Cursi es el pudor del bien [...] Épocas de cursilería compartida fueron épocas modestas, felices y pacíficas. (Gómez de la Serna, 1943, pp. 12 y 19)

En este tipo de sociedad, promotora de una literatura y un arte cursi que omite toda expresión del amenazante espacio público y que atenúa las 'tormentas' de la moral privada, vemos surgir el motivo lírico de la cuna vacía ${ }^{10}$ Este último no solo es cursi en la medida en que embellece, espiritualiza o maquilla una realidad dolorosa, sino que también, como motivo de moda, fue empleado premeditadamente por muchos poetas con la intención de conseguir en sus lectores un efecto sentimental planificado de antemano, con lo que nos ubicamos en el terreno de la definición que nos ofrece Umberto Eco del arte kitsch, en Apocalípticos $e$ integrados, en el sentido de arte epigonal que recupera procedimientos cuya eficacia sentimental ya ha sido demostrada en el pasado. ${ }^{11}$

El motivo de la cuna vacía está vinculado a la promoción de la infancia como máxima expresión de inocencia y pureza, valores asignados a esta categoría etaria en el discurso burgués. Frente a la supervivencia del más fuerte en el espacio público y sus potenciales amenazas, la sociedad 'acomodada' necesitaba, por contrapartida, un refugio que le proporcionara certidumbre y bienestar. En el marco del descanso del 'guerrero', el burgués favorecía, en sus 'dominios' privados, la ideología de la sensibilidad, la modosidad, la delicadeza, la ternura y lo conmovedor. En el hogar, es sagrado el espacio que circunda al bebé que duerme en la cuna: su paz no se debe perturbar. ${ }^{12}$ Sin embargo, esta última podía ser quebrantada por un acontecimiento: la muerte. La cuna se convertía, de pronto, en un ataúd. En estas circunstancias, los familiares atenúan el dolor del deceso mediante su espiritualización. La muerte se convierte, en consecuencia, en una ocasión para 'celebrar': el alma del niño se unirá con Dios y vivirá por siempre feliz, al mismo tiempo que su sufrimiento terrenal -producto de una dolorosa enfermedad- desaparece definitivamente.

La sociedad burguesa no puede negar la muerte infantil; sin embargo, puede atemperarla, atenuarla, tratarla con pudor, con reticencia. Bajo este propósito, el poeta que utilizaba el motivo de la cuna vacía recurría a la perífrasis eufemística, a nivel discursivo (identificable en el conjunto de un texto) y ya no solo a nivel retórico (discernible en una palabra o grupo de palabras). En particular, la perífrasis eufemística es un rodeo semántico que se fundamenta en la censura verbal de palabras que se consideran inconvenientes, desde la tradición de la decencia, la urbanidad o el respeto hacia la sensibilidad de los demás (Mortara-Garavelli, 2000, pp. 194-195). Aplicado este recurso a la situación que nos ocupa, el motivo de la cuna vacía no narra literalmente el deceso del bebé o del niño pequeño, sino que alude indirectamente a este último acontecimiento. En ocasiones, la perífrasis aparece como tropo compuesto (Mortara-Garavelli, 2000, p. 196) y así ocurre en el presente caso: la cuna, 
el 'contenedor', es metonimia de su 'contenido', el bebé. Paralelamente, la 'cuna vacía' alude a la desaparición del cuerpo o del alma del niño de este 'contenedor'. Como procedimiento discursivo, es utilizado, por ejemplo, por Ernest Hemingway, a quien se atribuye ${ }^{13}$ uno de los relatos más cortos de la literatura occidental: "For sale: Baby shoes. Never worn." ("Vendo zapatos de bebé, sin usar") (en Eklund, 2009, p. 108). Repleto de presupuestos e implicaturas, este minirelato incentiva la decodificación pragmática, es decir, la colaboración interpretativa del lector. Posiblemente, los padres compraron los zapatos antes del parto de la madre y el bebé murió al nacer.

En particular, se utiliza la perífrasis eufemística como una autocensura moral: si el cristianismo aprecia en la unidad con Dios la finalidad de la vida humana, sería una contradicción lamentar la muerte física. ${ }^{14}$ Mediante un rodeo semántico, los poetas 'aluden' a la muerte del infante como un 'descanso', un 'sueño' o un 'viaje', en términos metafóricos: no emplean los términos 'muerte' o 'cadáver', palabras consideradas obscenas, pornográficas... Su utilización en una elegía en recuerdo del deceso real de un niño sería incluso humillante para los padres, ya que daría a entender al lector que no fueron lo suficientemente diligentes y amorosos como para preservar la vida de su propio hijo. Aparte del tabú que impera en la representación de la muerte en Occidente, y más cuando se trata de un niño, la explicación genética (biográfica) sobre el origen de muchos de los poemas que utilizan el motivo de la cuna vacía también permite explicar su tratamiento eufemístico. Señalan Díez-Rodríguez y Díez-Taboada (2005, p. 328) que, estos poemas son, con frecuencia, en la historia de la literatura, "elegías por la muerte real y verdadera de una criatura concreta a cuyos padres -amigos del poeta o relevantes personalidades con los que éste quería bienquistarse- se dedica la composición". Como se dice popularmente, 'no debe hablarse de la soga en la casa del ahorcado'; el recuerdo elegíaco que ofrece el autor en su poema no debe 'activar' el dolor 'inconsolable' o la indignación de los padres, amigos del escritor, mediante la expresión de un término demasiado literal o 'gráfico', sino que debe suponer un medio de apaciguamiento de su angustia, al sugerir que el alma del hijo ingresará en el reino de los cielos. En particular, cuando el padre sufre esta tragedia y es un artista, sublimará el sufrimiento producido por la pérdida de su hijo mediante el proceso creativo. Un ejemplo reciente lo ofrece la canción Tears in Heaven (1992), escrita por Eric Clapton y Will Jennings, compuesta con motivo de la muerte accidental del hijo del primero, Conor Clapton, a la edad de 4 años.

El uso de la perífrasis eufemística es uno de los procedimientos más recurrentes del Posromanticismo, corriente estética que prefiere nombrar las experiencias sentimentales y emotivas, tanto las eufóricas como las dolorosas, mediante la alusión, la sugerencia, la reticencia, no solo desde la misma práctica poética, sino también desde el discurso de la teoría literaria. Así, por ejemplo, el poeta posromántico José Selgas, en su Discurso de ingreso a la Real Academia Española de la Lengua (1869, p. 11), considera que la comunicación íntima entre los amantes se establece en las miradas, el calor de los suspiros y el encanto de las sonrisas, más que en las palabras y las definiciones de los diccionarios. Estas reflexiones son similares a las formuladas por Gustavo Adolfo Bécquer (1988, pp. 239 y 241-242) en la "III Carta Literaria a una mujer”, al plantear que las imprecisas definiciones de las experiencias sentimentales no llegan a satisfacer y que la poesía se expresa mejor desde los murmullos, las sonrisas, las lágrimas, los suspiros y los deseos, más que desde las exaltaciones de la pasión. Selgas también sitúa estas reflexiones en el ámbito de la infancia. El sentimiento que nos embarga ante la presencia de un niño es tal que esta experiencia es racionalmente indefinible, 
intraducible. En su ya mencionado Discurso de ingreso, considera que la pureza de un niño no se puede traducir en palabras, sino que solo se puede apreciar en la inocencia de su belleza física:

\footnotetext{
Ved al niño que sonríe en el regazo de su madre: sus labios no han aprendido aún a pronunciar palabra alguna; pero su alma está toda en la expresión angelical de su rostro; todavía no ha tenido por qué ocultarla y la deja ver en la viva inquietud de sus ojos, en la dulce movilidad de su boca, en la agitación de sus pequeñas manos, en la pureza de su risueña frente.

Cosa extraña: no sabe hablar y todo lo dice. (Selgas, 1869, p. 11)
}

El alma (es decir, la emoción, el sentimiento), que en el caso del bebé y del niño pequeño están caracterizados por la ternura, la inocencia y la pureza, se comunican con total plenitud desde su expresión corporal. Todavía es incapaz de articular palabra. Su gestualidad y su belleza física expresan, por sí mismas, su inmaculada humanidad.

\section{El motivo de la cuna vacía en el Posromanticismo literario y pictórico}

En el Posromanticismo español hemos identificado diversas manifestaciones del motivo de la cuna vacía. En primer lugar, queda actualizado en dos poemas del murciano Andrés Blanco García (1849-1916), específicamente en "Junto a la cuna vacía" y en "Angelicos al cielo". En este último caso, el sufijo -ico es afectivo: intensifica la afectividad de una metáfora, el ángel, que de por sí ya idealiza -mediante una metáfora- al bebé que sustituye.

Si bien cuentan con algunos recursos macabros, también podemos incorporar en el corpus que manejamos los poemas "Una cuna vacía y un féretro lleno" (1851), de Robustiana Armiño (1821-1890) y "Angelitos al cielo", de Antonio Ros de Olano (1808-1886). El título del poema de Armiño, teniendo en cuenta el motivo que nos ocupa, es uno de los menos eufemísticos. Si bien la 'cuna vacía' alude solo indirectamente al cadáver de un bebé, mediante perífrasis, ya que la cuna ha dejado de cumplir sus funciones prototípicas, el 'féretro lleno', en cambio, manifiesta más bien el cumplimiento de sus funciones: albergar un cadáver.

También "Angelitos al cielo", de Antonio Ros de Olano (2009), ofrece una visión tremendista de la muerte de un bebé, alejándose del eufemismo. En este poema narrativo, el yo enunciativo se encuentra ante la comitiva -formada por niños- de un entierro gitano, que sale de la casa de los padres del fallecido y llega hasta el camposanto. Una vez arrojado el cuerpo desnudo del bebé a la fosa común, la comitiva infantil regresa al hogar. El poema termina con el contraste entre el baile de la fiesta iniciada por este último grupo y el llanto desesperado de la madre. La situación macabra no radica en el traslado del cadáver de la cuna al ataúd, como en el poema de Robustiana Armiño, sino en la utilización, por parte de la comitiva infantil, de la oximorónica cuna-ataúd, es decir, de una cuna que cumple la función de un ataúd. Dos veces se menciona la cuna. En la primera ocasión, el narrador testigo, que ha acompañado a la comitiva, atisba con sorpresa, a mitad del poema, que el grupo de niños arroja el cadáver a una fosa común: “iLas criaturas/ llevaban otro niño/ muerto en la cuna!/«iAngelitos al cielo!»”,/ gritaron todos, / y el menudo cadáver/ cayó en el foso:/ fue dando vuelcos/ y quedó boca abajo/ besando el suelo." (Olano, 2009). La altísima mortalidad de los niños recién nacidos entre las clases obreras se menciona mediante las repetidas idas al cementerio de cunas convertidas en ataúdes ('llevaban otro niño muerto en la cuna'). Se trata de un poema en el que se combina una representación áspera, ruda, fría, del acontecimiento -el cadáver que va dando vuelcos- con la atenuación metafórica de su truculencia (discernible en el cadáver que, boca abajo, 'besó' el suelo, o en las palabras eufemísticas -'Angelitos al cielo'- proferidas por la comitiva infantil). 
La cuna, en su función metafórica de ataúd, se menciona de nuevo cuando el grupo regresa a la casa paterna: "Ataúd que va y vuelve/ cuando es de pobres,/ pero, en vida del niño,/ vaso de flores..., tornar veían/ padre y madre la triste/ cuna vacía." [la cursiva es añadida] (Olano, 2009). En esta segunda ocasión, se menciona explícitamente el nombre del motivo lírico.

Un poema de escasa calidad literaria es "Junto a la cuna vacía", de Francisco Pérez Echeverría, aparecido en el Álbum Poético Español (1874). Ante una cuna vacía, una madre, en llanto silencioso, llega por breves momentos a 'ver' a su hijo, hasta que la alucinación se retira y solo queda la evidencia de la ausencia. La estrofa final retrata el dolor maternal ante la muerte infantil como el mayor de los sufrimientos que un ser humano puede soportar. Con razón el poema de Pérez Echeverría incorpora el adverbio locativo "junto a...”, ya que se focaliza en el dolor de una madre ante la mirada de la cuna vacía, objeto que activa el

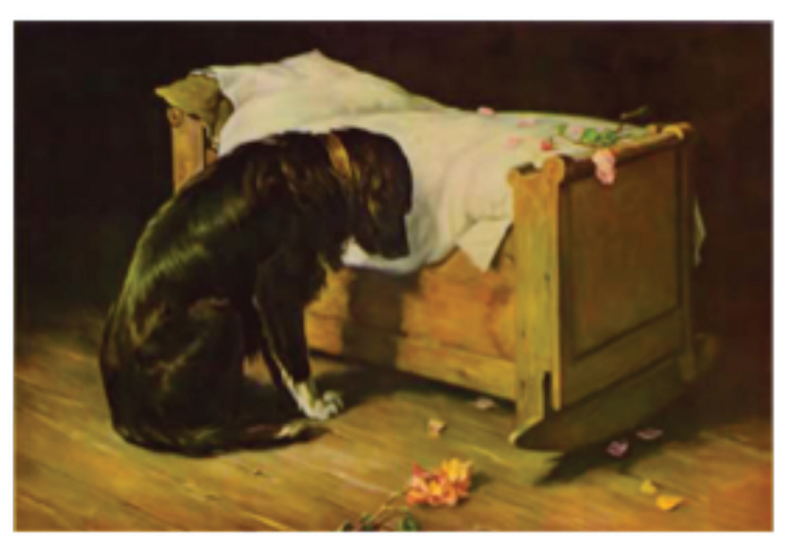

Imagen 1. La cuna vacía, de Gustave Henry Mosler (1875-1906) recuerdo del hijo desaparecido, antes que en la espiritualización de la muerte de este último.

De hecho, las representaciones visuales - pictóricas- del motivo deberían llamarse 'junto a la cuna vacía', en razón de la focalización externa utilizada. Al igual que en la literatura, en la pintura se desarrolló en la segunda mitad del siglo XIX y, asimismo, también se utiliza en esta práctica la perífrasis eufemística, que los semióticos de la imagen han estudiado preferentemente en el ámbito de la sexualidad, como ocurre con Carrere y

Saborit (2000, pp. 375-382), pero que también se muestra en las representaciones visuales de la muerte. Hemos identificado cuatro muestras: La cuna vacía, de Gustave Henry Mosler (18751906), La cuna vacía, de Jacobus Leinsten (1844-1918), La cuna vacía, del pintor asturiano Luis Meléndez Pidal (1861-1932), y La cuna vacía, 1871, del pintor mexicano Manuel Ocaranza (1841-1882). En todos estos cuadros, el centro de atención no lo reviste la espiritualización de la muerte, mediante la llegada de unos ángeles que invitan al alma del bebé a marcharse con ellos (la experiencia sobrenatural), sino que el interés de los pintores radica en retratar -en escenas de corte realista- las manifestaciones visibles de dolor, contenido siempre, que muestran a familiares, conocidos e incluso mascotas alrededor de una cuna vacía. Se sigue utilizando la perífrasis eufemística, esta vez visual. Si en los poemas se evita el término muerte, en las pinturas se elude mostrar el cadáver.

En el cuadro La cuna vacía, de Mosler (Imagen número 1), se visualiza el lecho, que ha dejado de cumplir su función, abrigar el cuerpo vivo de un bebé. Ante él se encuentra un perro que, con tristeza, está postrado ante el lugar ocupado previamente por el niño, una mascota que -puede inferir el espectador- le custodió, cuidó y jugó con él. A diferencia de los demás cuadros, que representan el momento inmediatamente posterior al deceso, la ausencia de personajes humanos en el cuadro de Mosler permite inferir que ha transcurrido un lapso mayor de tiempo (unas horas o unos pocos días). Ofrece un dolor todavía más contenido que el mostrado por las restantes pinturas, desde el dolor de un animal que no comprende lo que acaba de ocurrir. 
La cuna vacía, de M. J. Leinsten, representa una alcoba, lujosamente amueblada, de una familia de la alta burguesía. La madre se encuentra arrodillada y llora desconsoladamente sobre la cuna, cercana a la cama del matrimonio. El cadáver del bebé se encuentra oculto. Se representan, muy posiblemente, los momentos inmediatamente posteriores a la agonía del niño. Dos mujeres -amigas o hermanas de la madre- sollozan de pie con pañuelos que se llevan a la boca, mientras a su izquierda un monje presencia la escena. ${ }^{15}$ De nuevo, la focalización externa describe las consecuencias que el suceso ha producido en sujetos adultos que rodean al lecho infantil.

También es el caso de La cuna vacía, del pintor asturiano Luis Meléndez Pidal, que visualiza el dolor y el llanto de la familia. Se han llevado el cadáver del niño y la cuna se encuentra vacía. Los personajes adultos ya no miran la camita. La madre, arrodillada y sumida en la desesperación, posa su cabeza en la rodilla del marido, sentado en una silla, cabizbajo. Un personaje femenino de espaldas, posiblemente la abuela, despide en la puerta de la habitación a los restantes hijos -pequeños todos ellos- de la familia.

El más intimista de todos estos cuadros procede de La cuna vacía (1871) (Imagen número 2), del mexicano Manuel Ocaranza. ${ }^{16}$ Solo se muestra a la joven madre, que se encuentra en actitud de duelo. Enlutada y llorosa, recoge la ropa de cama de la cuna, indicador de la presencia previa de un bebé vivo. Asimismo, una cofia descansa sobre el extremo superior de uno de los travesaños de la camita. El momento de máximo dolor parece haber pasado: los recuerdos del niño (su ropa) pasarán a quedar guardados, como fetiches, en el armario.

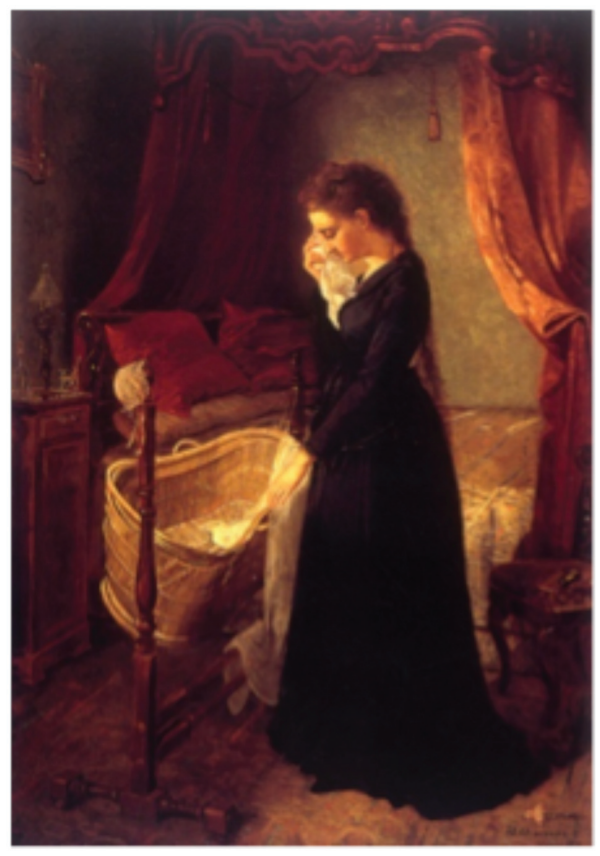

Imagen 2. La cuna vacía, de Manuel Ocaranza. Óleo sobre tela (1871)

\subsection{El motivo de la cuna vacía en el Posromanticismo español: José Selgas y Rosalía de Castro}

En primer lugar analizaremos el poema "La cuna vacía", del murciano José Selgas (1824-1882), cuya génesis se encuentra en la temprana muerte de sus dos primeros hijos, Justina y Carlos. Apareció originalmente en el periódico La moda elegante ilustrada en 1864, como demuestra Aranda-Muñoz (1993, p. 37), y quedó incorporado en su tercera colección de poesías, Flores y espinas, publicada en 1879. Es un poema integrado, por lo general, en las antologías dedicadas a la poesía del siglo XIX o que cuentan con secciones asignadas a este último siglo (por ejemplo, Díez-Rodríguez y Díez-Taboada, 2005, p. 327; Díaz-Plaja, 1961, p. 1239). Su popularidad se ha mantenido, sin que decaiga con el tiempo. Está dividido en cuatro estrofas y se encuentra segmentado en dos escenas. En la primera, de tono espiritual, los ángeles descienden a la cuna e invitan al niño a irse con ellos. Este último acepta la propuesta. La segunda, de tono realista, describe la cuna vacía. Esta estructura ya la observó Eusebio Aranda-Muñoz (1954, pp. 152-153) en su tesis doctoral, al apreciar que al final de la primera escena -que termina con el 
verso 'y se fueron todos'- la habitación queda en silencio y quietud. A nivel enunciativo, el acontecimiento es relatado por una voz extradiegética. En dos ocasiones, esta última delega el discurso en estilo directo a dos personajes, los ángeles y el bebé:

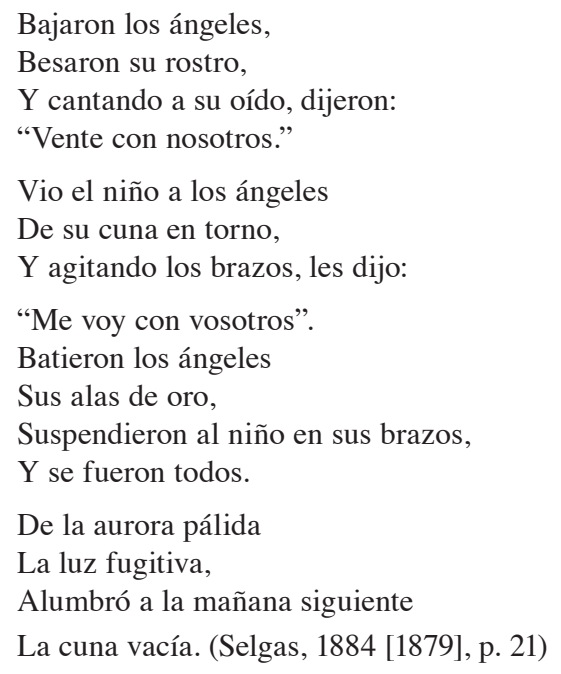

El poema de Selgas tiene una corta extensión. Por lo general, el motivo de la cuna vacía se expresa en poemas de pocos versos caracterizados por una alta concentración expresiva. Se trata de un caso de homología forma-contenido: la contención del sentimiento se expresa desde una estilística concisa. Además, más allá de su aparente sencillez denotativa y connotativa, los poemas que emplean este motivo guardan un complejo contenido implícito que el lector competente debe actualizar.

La acción que ocupa la primera estrofa es la siguiente: los ángeles descienden a la Tierra para llevarse el alma del bebé. Son seres que habitan en el Cielo, junto a Dios, y bajan para entrar en contacto con el alma del ser humano. La acción de los ángeles, la de 'descender' y encontrarse con el alma del bebé, se estructura a partir de una metáfora espacial de tipo orientacional: el Cielo -el mundo espiritual- se encuentra arriba, y la Tierra -el mundo material- abajo. La muerte del bebé supone, metafóricamente, el traslado del alma del ser humano de la Tierra (abajo) al Cielo (arriba). La imagen del 'descenso' a la Tierra de los ángeles para llevarse el alma del sujeto que agoniza se representa, asimismo, en el poema "Una cuna vacía y el féretro lleno", de Robustiana Armiño: "Rubios querubes/ Que el dulce coro/ Del arpa de oro/ Entonáis a los pies del señor;/ Ya la luna en las nubes oscila,/ Descended en la noche tranquila,/ Revolad de la cuna en redor." [la cursiva es añadida] (1851, p. 122). La difusión de la espiritualización de la muerte del bebé -en la cultura burguesa española- a través del llamado de los ángeles -que 'bajan' hasta la cuna para volver a 'ascender' al Cieloqueda de nuevo recalcada al final de la novela Torquemada en la hoguera (1889), de Benito Pérez Galdós, cuando agoniza Valentín, el hijo del usurero Francisco Torquemada. Rufina le comunica a su padre que, en el momento de morir, su hermano le dijo que veía ángeles que le llamaban. Torquemada, en un ataque de desesperación, interpela imaginariamente a su hijo -ya fallecido- para que rechace la solicitud de los ángeles: "No vayas; no hagas caso; que esos son unos pillos que te quieren engañar...Quédate con nosotros.” (Pérez-Galdós, 1998, p. 72). Un último ejemplo, procedente también de Galdós, el inicio del cuento "La Mula y el Buey (cuento de Navidad)", fechado en diciembre de 1876, incorpora de nuevo la función mediadora del 
ángel entre el mundo terrenal que abandona el bebé y el celestial en el que ingresa: "Cesó de quejarse la pobrecita, movió la cabeza, fijando los tristes ojos en las personas que rodeaban su lecho, extinguióse poco a poco su aliento, y expiró. El Ángel de la Guarda, dando un suspiro, alzó el vuelo y se fue." (Pérez-Galdós, 2008, p. 137).

El motivo lírico de la cuna vacía pretende representar una situación dolorosa como un acontecimiento sereno para el niño y como una oportunidad para que se incorpore a una existencia más feliz, la vida celestial junto a Dios. Es el caso de la voz enunciativa de "En la muerte de un adolescente”, de García de Quevedo: “Dichoso tú que ya de los azares/ Libre te ves del mundo, caro niño!" (1857, p. 171); o de "A mi sobrino Heriberto...", del mismo escritor: "Miras a tus pies al mundo/ Con sus pompas y martirios./ Libre te ves, tú el dichoso/ Allá en seguro asilo,/ De sus terribles pesares,/ De sus placeres mentidos" (1857, p. 83). Por su parte, la voz lírica de "En la muerte de un niño", de Zenea (1860, p. 32) enuncia esta misma creencia desde la siguiente invocación: "Sonriamos de placer, porque no cabe/ Desencanto profundo/ Al verlo que se ausenta y que no sabe/ Cuánto hay de amargo y triste en este mundo". Por último, el Duque de Rivas (1854, pp. 410-411) plantea esta visión esperanzada de la muerte en "Elvira": "Porque tu muerte es gloria,/ Que te alza de este mundo detestable, / Átomo miserable,/ De la inmensa creación perdida escoria;/ Y a la mansión te encumbra/ De bienandanza y vida sempiterna,/ Que con su luz eterna/ El rostro santo del Criador alumbra".

En esta cultura de católicos creyentes, la española del siglo XIX, el bebé no solo se convierte en un ángel más en el momento de morir; antes de su fallecimiento era, además, un ángel terrenal. Tres atributos compartidos por ambos seres permiten estructurar la metáfora del bebé como ángel: la belleza física, el carácter asexuado y la inocencia (ausencia de mácula moral, de pecado). ${ }^{17}$ Valis (2002, p. 248) menciona dos de estos atributos compartidos al explicar que, en la época de la Restauración borbónica (1873-1902), las representaciones artísticas y literarias del hijo muerto 'angelizan' su figura, al quedar perfilado desde la belleza y la inocencia. La identidad entre el bebé y el ángel queda expresada en un poema poco conocido que emplea el motivo de la "cuna vacía, "¡Vuelve al cielo! A un niño" (1875), de Javier Soravilla: "Niño, tus alas extiende,/ Cruza el espacio, ángel bello" (en Valis, 2002, p. 251). La acción relatada en el título del poema reproduce una imagen poética popular: el niño que muere muy pequeño no hace sino regresar al Cielo, junto con los demás ángeles, sus compañeros de juego. Mientras tanto, el interludio terrenal fue breve y doloroso. La imagen del bebé que regresa a su hogar original celestial también se emplea en el poema "A la memoria del niño Ignacio Nestares y Bueno", de José Zorrilla:

\footnotetext{
«Ángel que quiso visitar la tierra,/ Ser por Dios hecho de su Ser divino,/ No encontró en el ambiente que le encierra/ Ni aire a su aliento, ni a sus pies camino:/ Y ángel de paz, no hallando más que guerra,/ Abriendo el nicho que sobre él se cierra/Al cielo se volvió de donde vino» (en Ayuso-Rivera, 1959, p. 142)
}

Asimismo, en el ya mencionado poema "La opinión. A mi querida prima Jacinta White de Llano, en la muerte de su hija", de Ramón Campoamor, el poeta, al pasar el féretro de la pequeña, expresa: “đUn ángel más!” (en Díez-Rodríguez y Díez-Taboada, 2005, p. 329). En suma, por cada niño que muere aumenta el número de ángeles que forman las huestes de Dios. Se utiliza la conceptualización de la muerte como una continuación de la vida (Tod ist weiterleben) (Schwarz-Friesel, 2007, p. 264). El deceso del niño no significa el viaje a la nada; supone el tránsito a una existencia más gratificante que la terrenal. Además, la muerte del niño le impedirá sufrimientos en su vida adulta. Juan Clemente Zenea, en el poema "En la muerte 
de un niño" (1851), ve en este acontecimiento un desenlace positivo para el infante, no porque regrese al cielo, sino porque le evitará toda una vida de sufrimiento:

Cuando perece un ser, tierno pimpollo,/ Hijo de horas serenas/ Que no llegó a completo desarrollo/

Porque faltó la savia entre sus venas;/ Sonriamos de placer, porque no cabe/ Desencanto profundo/ Al

verlo que se ausenta y que no sabe/ Cuánto hay de amargo y triste en este mundo. [la cursiva es añadida]

(Zenea, 1860, p. 32)

En el poema "A un hijo de españoles arropamos", Unamuno pone en boca del progenitor esta actitud consolatoria, ya no en relación con una dolorosa enfermedad pasada, sino con la desafortunada vida que -como hijo de exiliados- se le avecinaba en el futuro, en su vida adulta: "«Ante la vida cruel que le acechaba/ mejor que se me muera», nos decía/ su pobre padre, y con la voz temblaba” (Unamuno, 2007, p. 61).

En el poema de Selgas, los ángeles actúan para lograr que la transición entre la vida y la muerte sea lo menos 'dolorosa' posible. Estos seres celestiales establecen una relación de confianza con el bebé basada en la ternura. Besan su rostro: le dan a entender que buscan su bienestar. Cuando se dirigen al niño, lo hacen cantando y, más que comunicar una orden, formulan una solicitud: "Vente con nosotros". La dirigen mediante el susurro de un canto dirigido al oído. No son ángeles de la muerte, sino ángeles enviados de Dios que prefiguran la dicha divina que le aguarda al alma del bebé. Tiene la capacidad visionaria de ver a otros ángeles -sus semejantes- y de identificar esta experiencia como la 'realidad'.

Pero no siempre se asocia el ángel y la muerte del niño con la invitación serena del primero al segundo para que le acompañe en la vida eterna. El ángel también puede estar compungido a causa del deceso, por lo general ante el sarcófago infantil, motivo más propio de la escultura funeraria que de la poesía. Este esquema compositivo, el del ángel que llora ante la tumba infantil, y que prolifera en el arte funerario kitsch del siglo XIX, queda caricaturizado desde la parodia en el Capítulo 1 de la novela La de Bringas (1884), de Galdós. El narrador llama 'angelón' al ángel que llora ante una lápida, por las 'buenas' proporciones que exhibe, e incluso se 'atreve' a asignarle un sexo, el masculino, cuando describe una acción impropia del sexo viril, al taparse los ojos llorones, avergonzado. ${ }^{18}$

En la representación del motivo de la cuna vacía se encuentra ausente o simplemente aludida una problemática que no hemos discutido hasta ahora: la enfermedad, la causa de la muerte del niño. Se eliminan sus síntomas y sus secuelas corporales. La muerte como misterio incomprensible se refuerza ante el hecho de que el dolor se ha cebado contra una persona inocente, libre de pecado. Este motivo lírico supone la espiritualización de un proceso físico, el sufrimiento que deja la enfermedad en el infante.

Aunque no forma parte del poema de Selgas, en ocasiones se incorpora en la representación del hecho luctuoso un juguete roto u olvidado, que alude a la vida truncada por la enfermedad. Supone para los padres un fetiche del niño muerto, al igual que los rizos de su cabello. La función fetichista cumplida por el juguete infantil queda claramente formulada por el narrador en el cuento "La mula y el buey (Cuento de Navidad)", de Galdós, ya comentado. En el presente caso, los juguetes son las figuras del pesebre: 
Las figuras no solo recuerdan a la madre los juegos de su hija. Además, aluden al dolor de su enfermedad: el juguete roto es una alegoría de la niñez truncada. Este valor fetichista otorgado por los padres a los juguetes de sus hijos forma parte de su duelo. Recordemos, como señala Freud (1984, pp. 241-242), que este proceso, supone la reacción -desinterés hacia el mundo exterior, incapacidad para escoger un nuevo objeto de amor- provocada por la pérdida de una persona amada.

La última estrofa del poema de Selgas también cobra una importancia sustancial en la construcción de la perífrasis eufemística del deceso. Ha de entenderse que los ángeles se llevaron el alma, aunque el cadáver del bebé todavía se encuentre en la cuna. Del lecho está ausente la entidad más trascendental: su alma -el contenido espiritual de la personase ha alejado.

El motivo de la cuna vacía pretende transmitir la esperanza en la posibilidad de la vida más allá de la muerte y el uso de la luz, en el poema, quiere expresar este optimismo. El bebé ha muerto durante la noche. La mañana subsiguiente, en el marco del tono sereno que nos transmite el poema, no es gris o lluviosa. En los primeros momentos del alba, la luz entra por la ventana de la habitación e incide sobre la cuna vacía. Simboliza la esperanza: el bebé se ha reunido con Dios. Se despliega alrededor del lecho un aura o aureola de santidad. La elección del verbo 'alumbrar' habla de la potencia espiritual, más que material, de esta luz. La del alba todavía no calienta el día, pero cuando llega a 'palpar' sobre la cuna convierte a esta última, símbolo de la santidad del bebé difunto, en un objeto deslumbrante, en un espacio sagrado. El alba simboliza el 'nacimiento' del bebé a una segunda vida, la espiritual, más plena y feliz que la terrenal. Además, es necesario precisar que, en el poema, la isotopía ${ }^{19}$ de la luz también se ofrece en las alas de oro de los ángeles. ${ }^{20}$

Si tomamos en cuenta el conjunto del poema de Selgas, es interesante analizar el procedimiento rítmico del estribillo, en el que se presentan distintas variantes. En primer lugar, los ángeles emiten la solicitud: "Vente con nosotros". En segundo lugar, el niño acepta la oferta: "Me voy con vosotros" y, en tercer lugar, desde la voz del hablante lírico, se relata la ejecución de la acción: "Y se fueron todos". Se puede vincular este estribillo con variación, asimismo, con el epifonema final, "la cuna vacía", pues el resultado de abandonar la cuna, ante la invitación de los ángeles, es dejarla vacía.

Aunque no menciona explícitamente el lecho del bebé, el poema de Rosalía de Castro "Dulce sueño" ("Dulce sono"), de Hojas nuevas (Follas novas), 1880, es otra manifestación del motivo lírico de la cuna vacía. ${ }^{21}$ Mientras que este último sintagma es una metonimia eufemística del cadáver de un bebé que ha sido trasladado a un féretro, en cambio, el sintagma ‘dulce sueño' es una metáfora eufemística del fallecimiento. Sigue la tradicional equiparación trópica, en Occidente, entre el sueño y la muerte, no solo en la literatura, sino también en el lenguaje cotidiano, como ha destacado Schwarz-Friesel (2007, p. 263). Así, por ejemplo, el yo lírico de "Al niño enfermo", de Miguel de Unamuno, apostrofa al infante y le vaticina que dormirá en sus brazos -en los de la dulce Muerte- "el sueño eterno" (Unamuno, 2007, p. 52).

A continuación se ofrece el poema de Rosalía de Castro, de versos hexasílabos:

Bajaron los ángeles

adonde ella estaba,

hiciéronle un lecho

con las alas plácidas. 


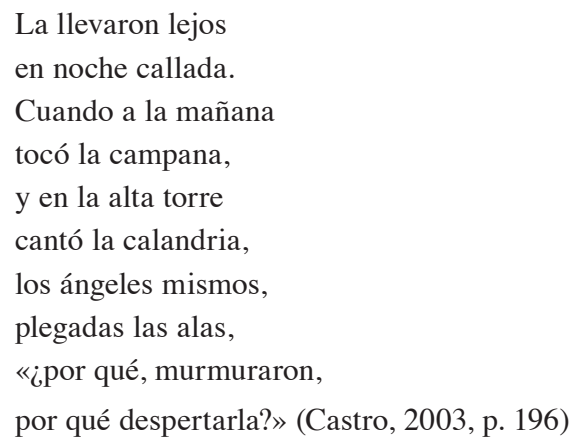

Se presentan algunas coincidencias con el poema de Selgas. Tanto el poema del murciano como el de Rosalía comienzan con la misma acción, expresada mediante las mismas palabras ('Bajaron los ángeles'). Asimismo, el deceso -aludido mediante la llegada de los ángeles, que toman el alma del niño- ocurre en la noche.

Pero en el poema de la autora gallega, a diferencia de Selgas, se identifica el sexo del bebé: es una niña. Además, ya no solo se habla de una cuna vacía, sino también de un lecho celestial; metonímicamente, hemos de pensar que ha ocurrido una transferencia por contigüidad del bebé de la cuna, en la que descansa su cuerpo (vida terrenal), al lecho de alas angelicales, en el que su alma queda depositada (vida celestial). Si comparamos ambos poemas, mientras los ángeles llevan al bebé en sus brazos en el poema de Selgas, convierten sus propias alas en lecho en el poema de Rosalía. No existe transición más suave -y menos dolorosa- hacia la muerte que este traslado de la cuna terrenal al lecho celestial o, más propiamente hablando, 'angelical'. Este último y el silencio de la noche ('noche serena') contribuyen a eliminar toda connotación traumática sobre la experiencia de la muerte de la niña.

La focalización sobre el acontecimiento cambia, en relación con el poema de Selgas. Este último presta mayor atención a la fase previa al deceso, mientras que Rosalía de Castro representa, sobre todo, los momentos posteriores. Además, alejándose parcialmente de la ambientación interior e intimista típica de este motivo lírico, se proyecta su simbología en el ambiente exterior, fuera del hogar. Tocan las campanas en el pueblo abúlico -hemos de inferir que tocan a muerto- y canta la calandria, pájaro que, según la creencia popular, anticipa la muerte a quien escuche su canto, pero que, en este caso, comunica al lector la existencia de un deceso previo. La espiritualización de la muerte queda reforzada por la isotopía de la verticalidad, presente en la alta torre, sitio desde el que cantan, complementándose, la calandria y las campanas. A su vez, esta isotopía denotativa alude, a nivel connotativo, a la espiritualidad que transmite el entorno físico. Al igual que en el poema de Selgas, el deceso se produjo en algún momento indeterminado de la noche y, como en el poema del murciano, se retrata la mañana posterior al fallecimiento. Esta última, aunque muestra indicadores de un reciente acontecimiento luctuoso, se muestra como serena, en concordancia con la esperanza cristiana: el alma alcanzará la felicidad en presencia de Dios.

La muerte traslada al bebé a un mundo mejor, más gratificante. De ahí que los ángeles -la voz colectiva de quien procede el discurso directo al final del poema- interpreten la posibilidad de despertar a la niña -de que resucite- como un absurdo, como un contrasentido (‘¿por qué despertarla?’). Precisamente este epifonema final se puede vincular directamente con el título del poema ('Dulce sueño'): si la bebé disfruta de un dulce sueño, el de su deceso, sosegado, sereno, ¿por qué despertarla?, es decir, ¿por qué resucitarla? 


\section{Conclusiones}

Junto con la práctica de conservar los rizos de los niños fallecidos, guardados como fetiches en joyeros y representados en incontables pinturas y versos (Valis, 2002, p. 249), el auge de los poemas que utilizan el motivo de la cuna vacía ha de asociarse a la práctica de atenuar el dolor mediante procedimientos compensatorios, promovida por la cultura burguesa del siglo XIX.

Llegó a ser un motivo lírico y pictórico ampliamente difundido en la cultura de la segunda mitad del siglo XIX. Y, como sucede con todo tema, tópico, motivo o figura literaria que obtiene éxito y es utilizado epigonalmente (es decir, deviene en kitsch o cursi), es objeto de burla. Este es un proceso típico del Romanticismo, que parodió sus propios temas, tópicos, motivos y figuras más recurrentes. En particular, el poema de Selgas cuenta con la parodia de José Fernández Bremón, La cuba vacía, como recoge la tesis doctoral de Eusebio Aranda-Muñoz, Selgas y su obra (1954, p. 152). Galdós, que se burla en numerosas ocasiones de la cursilería en el habla cotidiana y en las costumbres de la burguesía madrileña -o de los sectores sociales con pretensiones burguesas-, también se hace eco paródico de las perífrasis eufemísticas cuando el narrador de la novela Fortunata y Jacinta comenta la muerte de un personaje adulto, Isabel Cordero, madre de Jacinta: "Su muerte fue de esas que vulgarmente se comparan a la de un pajarito. Decían los vecinos y amigos que había reventado de gusto." [en cursiva en el original]. (Pérez-Galdós, 1993, p. 72).

La amplia presencia del motivo de la cuna vacía en la literatura española del siglo XIX debe situarse, en todo caso, en las coordenadas más generales de la atracción que ejerce la muerte infantil en el Romanticismo europeo, a nivel estético, y en el marco de la sublimación de la idea de la muerte, promovida por la sociedad burguesa de la época. Su práctica no debe reducirse a los conocidos poemas de José Selgas y Rosalía de Castro.

El principal procedimiento discursivo del motivo de la cuna vacía es, tanto a nivel verbal como visual, la perífrasis eufemística. En las manifestaciones poéticas, la recepción del alma infantil por los ángeles y la descripción de la escena de la cuna vacía permiten evitar la mención directa de la muerte del niño y de su cadáver. Estos poemas establecen una antítesis: la dolorosa vida terrenal ha sido efímera (ha quedado interrumpida a los pocos días o meses), pero la celestial será eterna y dichosa. Los poemas de Robustiana Armiño y de Ros de Olano son los únicos que no emplean la visión espiritualizada de este acontecimiento desde la perífrasis eufemística y ofrecen, en cambio, una visión parcialmente grotesca de la muerte infantil. Por su parte, en las manifestaciones pictóricas de este motivo se representa el sufrimiento contenido de los familiares 'junto a una cuna vacía': esta focalización externa evita mostrar el cadáver infantil.

Ligado a la utilización de la perífrasis eufemística, el tono emotivo de estos poemas es sentimental, lejos de la pasión que domina en otras corrientes románticas (la social o la cívica, entre otras). Este tono explica, por ejemplo, la ausencia de la exclamación retórica, ligada a la pasión, a la efusión emotiva.

El motivo que ha ocupado la atención en el presente artículo encuentra una similitud emotiva con la representación de la muerte del hijo-combatiente. ${ }^{22}$ El dolor contenido también forma parte de las representaciones del duelo materno ante la pérdida del hijo en circunstancias bélicas, tema que puede ser objeto de futuras investigaciones. 


\section{Notas}

1. Algunos de estos poemas los hemos identificado a raíz de la enumeración, más o menos exhaustiva, ofrecida por Díez-Rodríguez y Díez-Taboada (2005, pp. 328-329).

2. En este poema, el cortejo fúnebre recorre su trayecto por la calle atestada de gente, camino el cementerio, y la voz enunciativa registra los comentarios que escucha entre el público espectador.

3. En este último no se expresa la emoción del yo-lírico ante la muerte de un infante, sino que representa un caso de epitafio escrito en primera persona -típico en el Romanticismo europeo-, desde la simulación del apóstrofe del sujeto muerto -en este caso, un niño- al paseante que se detiene a leerlo.

4. En este último, todavía caracterizado por el discurso alegórico del neoclasicismo, se compara el deceso del bebé con el capullo de un rosal que cae al suelo, antes de florecer.

5. Si nos ocupamos de otras latitudes, no se puede hablar de la presencia de este motivo en el Romanticismo alemán sin referirnos al famoso poema de Goethe, "El rey de los elfos" (1782), a partir del que Schubert compondría su famoso lied en 1815 del mismo título. Se trata de un poema narrativo en el que se ofrecen cuatro voces enunciativas, todos ellas presentes, asimismo, en la composición musical: la del narrador, la del rey de los elfos, que quiere llevarse a su reino el alma del niño, la voz de este último (que afirma ver al elfo) y el padre, que cabalga para tratar de salvar a su hijo. Se sugiere la muerte final del niño en el marco de una atmósfera fantástica, muy alejada de la sentimentalidad íntima que se aprecia en otras muertes infantiles del Romanticismo.

6. Esta voz establece la lectura alegórica del entierro del niño, que supone, en suma, una alusión a la desaparición de cualquier porvenir democrático para España, en el marco de la dictadura de Primo de Rivera: “creí que enterramos -¡Dios callaba!- tu porvenir sin luz, ¡España mía!” (Unamuno, 2007, p. 61). En esta voz poética apreciamos una transposición o proyección de las propias circunstancias vitales de Unamuno, exiliado en Francia, a partir de 1924, a raíz de su oposición a la dictadura de Primo de Rivera (1923-1931).

7. Recordemos "Ciudad sin sueño (Nocturno del Brooklyn Bridge)", de la sección "Calles y sueños": "y el niño que enterraron esta mañana lloraba tanto/ que hubo necesidad de llamar a los perros para que callase" (García-Lorca, 2003, p. 151); "Niña ahogada en el pozo (Granada y Newburg)", de la sección "En la cabaña del Farmer (Campo de Newburg)": "Pero el pozo te alarga manecitas de musgo/ insospechada ondina de tu propia ignorancia" (García-Lorca, 2003, p. 179); o "Iglesia abandonada (Balada de la Gran Guerra)" de la sección "Los negros": "Yo tenía un hijo que se llamaba Juan./ Yo tenía un hijo./ Se perdió por los arcos un viernes de todos los muertos./ [...] He golpeado los ataúdes. ¡Mi hijo! ¡Mi hijo! ¡Mi hijo!” (García-Lorca, 2003, p. 133).

8. Debe considerarse, en todo caso, que el símbolo de la cuna -sin el adjetivo 'vacía'- adquiere en la poesía lírica, en ocasiones, significados connotativos alejados de la muerte prematura de un niño de corta edad. Así ocurre en "La cuna", de la poeta posmodernista uruguaya Juana de Ibarbourou (1892-1979). Se trata de un panegírico, lleno de gratitud, dirigido el cedro del que procede la madera utilizada en la cuna del hijo de la hablante poética. Mientras observa a su hijo en el pequeño lecho, imagina la historia del árbol y establece la equiparación entre la protección que ofrecieron en el pasado sus ramas a los nidos de los pájaros, y la que le presta al infante, en el presente de la enunciación, la cuna procedente de la madera de cedro (Ibarbourou, 2011, pp. 225-226).

9. En particular, se buscaba convertir la sala de estar en una exhibición de objetos que, sinecdóticamente, y desde la seguridad del hogar, representaran la diversidad del mundo.

10. También en esta época cultural surgieron, por ejemplo, circunscribiéndonos a la Francia de Luis Felipe, el Rey Burgués, las fisiologías y géneros afines, textos que, preparados por el escritor flaneur, buscaban domesticar la amenazante realidad metropolitana de ciudades que aumentaban su población exponencialmente (Benjamin, 1998, pp. 49-83).

11. Umberto Eco, en Apocalípticos e integrados, también se ha ocupado de la literatura y del arte kitsch o cursi, aquellas prácticas culturales que buscan incentivar un efecto sentimental premeditado en el público mediante la recuperación de procedimientos que hayan demostrado previamente este tipo de reacción: "es 
Kitsch aquello que se nos parece como algo consumido; que llega a las masas o al público medio porque ha sido consumido; y que se consume (y, en consecuencia, se depaupera) precisamente porque el uso a que ha estado sometido por un gran número de consumidores ha acelerado e intensificado su desgaste" [en cursiva en el original] (Eco, 1993, p. 113). Es decir, etiqueta como cursi aquel arte compuesto predominantemente para incentivar una recepción emocional o sentimental (y ya no sentimental), cuyos procedimientos hayan previamente certificado este tipo de eficacia. El trasfondo teórico que opera en esta definición de Eco es el formalista. Según esta escuela de pensamiento, la evolución de la historia literaria se interpreta, de manera inmanentista, mediante la constante sustitución de procedimientos desgastados, por otros novedosos. Implícito en la definición de Eco es el abismo existente entre la práctica de los escritores renovadores y la de aquellos escritores epigonales que se acomodan a las expectativas del público mediante la utilización de recursos de probada eficacia, como sucede, por ejemplo, con la representación sentimental de ciertos temas, como puede ser, por ejemplo, el deceso de un niño.

12. El motivo del niño dormido en la cuna se emplea como término de comparación en la "Rima LXXVI", de Gustavo Adolfo Bécquer: "Me acerqué a la nave/ al ángulo sombrío,/ con el callado paso que se llega/ junto a la cuna donde duerme un niño".

13. Se trata de un caso de atribución dudosa, ya que nunca fue publicado en sus colecciones de cuentos.

14. La perífrasis eufemística también se puede utilizar para aludir indirectamente a la muerte de una amada, como ocurre en la "Rima LXXIII", de Gustavo Adolfo Bécquer: "Cerraron sus ojos/ que aún tenía abiertos, /taparon su cara con un blanco lienzo, / y unos sollozando, otros en silencio, /de la triste alcoba/ todos se salieron." (1988, p. 193). En este caso, se representa el momento posterior al deceso, al que se alude, indirectamente, mediante dos acciones, la de cerrar los ojos del fallecido y la de cubrir su rostro con un lienzo o sábanas. Estas últimas son dos imágenes tradicionalmente asociadas a la manipulación del cuerpo de un individuo recientemente fallecido. El tono del dolor ante la muerte de la amada, en la rima de Bécquer, también es el típico en las representaciones del motivo de la cuna vacía: el ambiente que domina no es de dolor desgarrado, sino de tristeza y dolor contenido; asimismo, antes que el llanto desbordado, domina el silencio respetuoso de familiares y amigos, solo roto por sollozos amortiguados.

15. He podido acceder a reproducciones de los cuadros de M.J. Leinsten y de Luis Meléndez Pidal a través del artículo de Fernández-Polo (1981). La primera se encuentra entre las páginas 22 y 23, y la segunda entre las páginas 24 y 25.

16. Es el único de los cuadros a cuya fecha de composición he podido acceder.

17. Esta asociación semántica entre el niño y el ángel, en todo caso, también entra en crisis. Así, por ejemplo, Miguel de Unamuno, en un contexto -el de fin de siglo- caracterizado por la crisis de la fe, sustituye los ángeles por la alegoría de la muerte: "Pronto vendrá con ansia/de recogerte/ la que te quiere tanto, la dulce Muerte." (Unamuno, 2007, p. 52).

18. Así describe el narrador el 'angelón' del conjunto funerario: "En el centro del mausoleo, un angelón de buen talle y mejores carnes se inclinaba sobre una lápida, en actitud atribulada y luctuosa, tapándose los ojos con la mano como avergonzado de llorar; de cuya vergüenza se podía colegir que era varón. Tenía este caballerito ala y media de rizadas y finísimas plumas, que le caían por la trasera con desmayada gentileza, y calzaba sus pies de mujer con botitos, coturnos o alpargatas; que de todo había un poco en aquella elegantísima interpretación de la zapatería angelical. Por la cabeza le corría una como guirnalda con cintas, que se enredaban después en su brazo derecho. Si a primera vista se podría sospechar que el tal gimoteaba por la molestia de llevar tanta cosa sobre sí, alas, flores, cintajo y plumas, amén de un relojito de arena, bien pronto se caía en la cuenta de que el motivo de sus duelo era la triste memoria de las virginales criaturas encerradas dentro del sarcófago." (Pérez-Galdós, 1994, p. 3).

19. Podemos definir la isotopía, desde la semiótica greimasiana, como aquella lectura semánticamente coherente u homogénea surgida a partir de la activación de los mismos significados en las palabras de un texto, mientras que otros quedan sin actualizarse. En palabras de Greimas (1973, en Pozuelo-Yvancos, 2009, p. 206), la isotopía es un "[c]onjunto de categorías semánticamente redundantes que hace posible la lectura de una historia tal como resulta de las lecturas parciales de los enunciados después de resolver sus ambigüedades". La isotopía de la luz se obtiene al activar su semántica, por ejemplo, de la lectura de términos como lámpara, sol, etc. 
20. Las alas de los ángeles también se representan en la historia de la pintura mediante el baño de oro (como en la conocida Anunciación, de Fra Angelico).

21. El original en gallego es el siguiente: "Baixaron os ánxeles/ adonde ela estaba,/ fixéronlle un leito/coas prácidas alas, e lonxe a levano/ na noite callada.// Cando á alba do día/ tocóu a campana,/ e no alto da torre/ cantóu a calandria,/ os ánxeles mesmos,/ pregádalas alas, («ipor qué -marmurano-,/ por qué despertala...?»" (Castro, 2003, p. 297).

22. También puede ser objeto de una futura investigación la asociación entre la cuna y el nido. Así, un motivo como el de la cuna vacía es utilizado en el diálogo que protagonizan dos hojas en el cuento Las hojas secas, de Gustavo Adolfo Bécquer. Una de ellas describe la llegada del otoño, cuando los nidos se quedan sin pájaros: "Y quedó el nido solo, columpiándose lentamente y triste como la cuna vacía de un niño muerto.” (Bécquer, 2007, p. 284). La semejanza semántica compartida por el nido y la cuna es el refugio, la protección, valores que permiten la transferencia metafórica entre los dos términos.

\section{Bibliografía}

Aranda-Muñoz, E. (1954). Selgas y su obra. Murcia: Cátedra Saavedra Fajardo/Universidad de Murcia.

Aranda-Muñoz, E. (1993). "La cuna vacía” de Selgas. Por A. Cano-Calderór就engua y literatura: su didáctica. Homenaje a la profesora Carmen Bautista Martín. (19-37). Murcia: Secretariado de Publicaciones de la Universidad de Murcia.

Armiño, R. (1851). Poesías. Oviedo: Imprenta y litografía de Martínez Hermanos.

Ayuso-Rivera, J. (1959). El concepto de la muerte en la poesía romántica española. Madrid: Fundación Universitaria Española.

Bécquer, G.A. (1988). Rimas y Declaraciones poéticas. (3 ed.). Madrid: Espasa-Calpe.

Bécquer, G.A. (2007). Las hojas secas. Por P. Izquierdo (Ed.). Narraciones. (280-285). Madrid: Cátedra.

Benjamin, W. (1998). El París del Segundo Imperio en Baudelaire. II. El «flaneur». Iluminaciones II. Poesía y capitalismo. (49-83). Madrid: Taurus.

Campoamor, R. (2005). La opinión. A mi querida prima Jacinta White de Llano, en la muerte de su hija. Por M. Díez-Rodríguez y P. Díez-Taboadd poesía lírica española. (328-329). Madrid: Cátedra.

Carrere, A. y Saborit, J. (2000). Retórica de la pintura. Madrid: Cátedra.

Castro, R. (2003). Poesía. [Selección, traducción e introducción de M. Armiño]. Madrid: Alianza Editorial.

Díaz-Plaja, G. (Dir.). (1961). Antología mayor de la literatura española. IV. Neoclasicismo, romanticismo, realismo (Siglos XVIII y XIX). Barcelona: Editorial Labor.

Díez-Rodríguez, M. y Díez-Taboada, P. (2005). Antología comentada de la poesía lírica española. Madrid: Cátedra.

Duque de Rivas (Ángel de Saavedra). (1854). Elvir $\bar{\equiv}$ bras completas. Tomo I. Poesías sueltas y poemas corso $\bar{\equiv}$ adrid: Imprenta de la Biblioteca Nueva.

Eco, U. (1993). Apocalípticos e integrados. Barcelona: Lumen. 
Eklund, D. (2009). The Pictures Generation, 1974-1984. New York: The Metropolitan Museum of Art.

Fernández-Polo, M.D. (1981). De nuevo «La cuna vacía», de Selgas. Monteagudo. 72, 21-28.

Ferrucci, F. (1989). The Dead Child: A Romantic Myth. MLN. 104, 117-34.

Freud, S. (1984). Melancolía y duelo. Obras completas. Volumen 14 (1914-1916). (2 ed.). (241255). Buenos Aires: Amorrortu.

García de Quevedo, J.H. (1857). Versos de J. H. García de Quevedo. Caracas: Imprenta de Sanojo y Escobar.

García-Lorca, F. (1998). Obras II. Poesía II. Romancero gitano. [García-Posada, M. (Ed.)]. Madrid: Cátedra.

García-Lorca, F. (2003). Poeta en Nueva York. (12 ed.). Madrid: Cátedra.

Gil, R. (1949). El último juguete. poesías de autores hispano-americanos, españoles y extranjeros. Buenos Aires: Librería Guadalupe.

Gómez de la Serna, R. (1943). Lo cursi y otros ensayos. Buenos Aires: Editorial Sudamericana. Ibarbourou, J. (2011). Las lenguas de diamante. Raíz salvaje. ed.). Madrid: Editorial Cátedra.

Lope de Vega, F. (1998). Poesía. $\equiv$ rcía-Posada, M. (Ed.)]. Madrid: Ediciones Libertarias.

Mortara-Garavelli, B. (2000). Manual de retórica. Madrid: Cátedra.

Olano, R. (2009). Angelitos al cielo. [pdf.]. http://www.biblioteca-antologica.org [Consulta 21 de marzo de 2013].

Pérez-Echeverría, F. (1874). Junto a la cuna vacía. Álbum Poético Español. (277-278). Madrid: Imprenta Esteroetipia y Galvanoplastia de Aribau.

Pérez-Galdos, B. (1993). Fortunata y Jacinta. Madrid: Turner Libros.

Pérez-Galdós, B. (1994). Obras completas. Novelas contemporáneas V: La de Bringas. Lo prohibido. Madrid: Editorial Turner.

Pérez-Galdos, B. (1998). Las novelas de Torquemada. Madrid: Alianza Editorial.

Pérez-Galdós, B. (2008). La Mula y el Buey (cuento de Navidad). Por A.E. Smith (Ed.). Cuentos fantásticos. (4 ed.). (137-155). Madrid: Editorial Cátedra.

Pozuelo-Yvancos, J.M. (2009). Teoría del lenguaje literario. (6 ed.). Madrid: Cátedra.

Saavedra, A. (1854). Obras completas de Don Ángel de Saavedra, duque de Rivas. Tomo I. Poesías sueltas y poemas cortos. Madrid: Imprenta de la Biblioteca Nueva.

Schwarz-Friesel, M. (2007). Sprache und Emotion. Tübingen und Basel: A. Francke Verlag.

Selgas, J. (1869). Discursos presentados a la Real Academia para la Recepción del Sr. D. José de Selgas y Carrasco. Madrid: Imprenta de J. Rivera.

Selgas, J. (1884). La cuna vacía. Flores y espinas (Colección de poesías). Veracruz: Librerías La Ilustración. 
Soravilla, J. (1875). ¡Vuelve al cielo! (A un niño). El Bazar. 3 (23), 366.

Unamuno, M. (2007). Antología. Poesía, narrativa, ensayo. Madrid: Fondo de Cultura Económica.

Urrutia, J. (2008). Poesía española del siglo XIX. Madrid: Cátedra.

Valis, N. (2002). Death and the Child in Su único hijo. Hispanic Review. 70 (2), 243-263.

Zenea, J.C. (1860). En la muerte de un niño. Cantos de la tarde. Elegías. Poesías varias. (3145). La Habana: Imprenta La Antilla.

Zorrilla, J. (s.f.). Obras de don José Zorilla. Tomo III. Obras poéticas y dramáticas. París: Casa Editorial Garnier Hermanos.

\section{Bibliografía de imágenes}

Imagen 1. Mosler, G.H. (1902). La cuna vacía. http://pinturaypoesia.blogspot.com [Consulta 8 de febrero de 2014].

Imagen 2. Ocaranza, M. (1871). La cuna vacía. [Oleo sobre tela]. http://www.inehrm.gob. mx [Consulta 5 de febrero de 2014]. En: Instituto Nacional de Estudios Históricos de las Revoluciones de México. Imagen tomada del libro: Curiel, G. et ál. (1999). Pintura y vida cotidiana en México, 1650-1950. (p. 186). México: Fomento Cultural Banamex/ Conacultap. 
